\title{
The Implicit Incentive Effects of Promotion Opportunities on Effort Provision
}

\author{
Konstantin Gruen ${ }^{1}$
}

\begin{abstract}
This study attempts to find a relationship between the implicit incentives provided by promotion opportunities and employee performance. It focuses on two different settings in which these incentives are present, namely situations in which the tasks to be performed after the promotion are similar as compared to the current job's tasks, as well as situations in which the tasks differ after the promotion. Both scenarios are analysed through two-step generalized method of moment tests using panel data from a Swiss retail bank between 2006 and 2012. From the analysis, two conclusions can be drawn. First, in situations in which the tasks to be performed after promotion are similar, the incentives provided by the promotion opportunity increase employees' effort provision. Second, in situations in which the tasks to be performed after promotion are different, there is no significant effect on employees' effort provision. In general, it appears that a distinction between the two settings should be made to enhance understanding of the promotion incentive and increase its effective use in practice. Future research can further investigate this relationship, for example by focusing on the effect of the incentive on changes in behavior that may not directly be related to employee performance or by further disaggregating the promotion incentive construct.
\end{abstract}

\section{Introduction}

Through company scandals such as Enron, WorldCom or Lehman Brothers, the issue of interest alignment between principal and agent has received an increased amount of attention from both public and academia in recent years (Heath, 2009). Generally, one of the main goals of such interest alignment is to prevent or at least decrease the probability of - opportunistic employee behaviour that may be detrimental to the owners of a firm and the general public. Interest alignment initiatives need to be carefully planned and executed, as alignment does not only come with associated benefits, but also with a variety of costs that need be taken into account (Coff, 1997). However, it has proven difficult to empirically examine implicit incentives in particular; theoretical frameworks are generally well established, but empirical evidence is often lacking (Ederhof, 2011). This is arguably due to the difficulty to attain relevant data for analysis. As a potential consequence, implicit incentives are often not considered when firms develop compensation contracts (Gibbs, 1995). The aim of this paper is to enhance understanding of the implicit incentive function of promotions by providing empirical evidence regarding the effect of promotion opportunities on effort provision. According to Gibbs (1996), promotions arguably represent the most important incentive present in companies.

This paper's findings indicate that a distinction between similar (Type S Incentive) and different (Type D Incentive) promotion incentives should be made. As such, the effect of the promotion incentive on effort provision differs depending on whether the tasks to be performed after the promotion are similar or different to the tasks performed in the current job. Specifically, Type S Incentives have a significantly positive effect on Sales Performance while the effects of Type D Incentives on Sales Performance are

\footnotetext{
${ }^{1}$ Konstantin Gruen received a bachelor degree in International Business at Maastricht University in 2013. At the moment he takes a Master in Accounting and Finance at the University of Sankt Gallen.

Contact: konstantin.gruen@student.unisg.ch
}

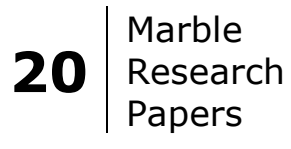


positive, but insignificant. As employees are likely to be evaluated based on their current job performance in Type S settings, they seem to adjust their performance upwards, increasing effort provision. Current sales performance appears to be a relatively straightforward measure of ability in the context of Type $S$ Incentives. Thus, it is a measure that is likely to be considered when making promotion decisions. Furthermore, from the employee point of view, there is a direct relationship between action and reward, resulting in a perceived fairness of evaluation (Feather, 1999). In Type D settings, other factors such as human capital acquired through training (Grabner \& Moers, 2016) may be more accurate indicators of ability. Employees with the Type D Incentive appear to take this into account, as the impact of this type of promotion incentive on effort provision is not significant.

In the next section, previous literature will be reviewed, highlighting important concepts and highlighting the proposed value of this paper. In the following section, this paper's research question and sample selection will be outlined. Afterwards, hypotheses will be developed and relevant variables will be discussed. Subsequently, the proposed relationships will be empirically analysed. In the successive section, the results of the analysis will be discussed and interpreted. Following, implications and limitations of the study will be highlighted. Finally, the paper summarizes with the main conclusions that can be drawn from the study.

\section{Literature Review}

Incentives are often analysed in context of agency theory with the aim to align interests of principal and agent, providing motivation to the agent to act in a desirable way (Garnefeld, 2012, Gibbons, 1998). The implicit incentives analysed in this study are promotion opportunities; they represent an implicit incentive as in the context of such opportunities, an "understanding" (Fried \& Howitt, 1980) between principal and agent is implicitly established concerning desired behaviour and the related reward for this behaviour. Promotion opportunities may have a significant impact on the principal-agent relationship as they represent one of the most important incentives present in companies (Gibbs, 1996). On average, most increases in compensation throughout a career can be linked to promotions (Medoff \& Abraham, 1980). Generally, there is the possibility for firms to design implicit contracts that provide steady compensation increases to employees unrelated to their relative ability and performance (Azariadis, 1975; Medoff \& Abraham, 1980) and thus for example make compensation and promotions a function of total tenure at the company. In practice, however, implicit incentives are usually not considered when compensation contracts are designed (Gibbs, 1995).

Companies typically do not pre-commit to promotions but rather have discretion in making decisions relating to promotions (Prendergast, 1999; Chan, 2016), which is why promotion opportunities represent an implicit incentive. Thus, an employee's motivation to behave in a desired way (Garnefeld, 2012) may be impacted when these opportunities are present and attainable. In academic literature, promotions are said to perform two functions, namely roles of incentive provision and sorting (Baker, Jensen, \& Murphy, 1988; Gibbs, 1995). Through the sorting function, also sometimes referred to as matching, employees are assigned to jobs that fit their abilities the best. This sorting function highlights the importance of ability, in contrast to current job performance, and may thus differ between different types of promotions. As such, indicators of ability need to be established by employers and it is likely that employees adjust their 
behaviour based on which indicator they are evaluated upon. The sorting function of promotions is sometimes referred to in the context of internal labour markets. Specifically, if the firm at which an employee is working has an asymmetric information advantage regarding employees' performance or ability as compared to information available to the external market, such a company may misallocate employees to jobs through the sorting function of promotions and thus deter from signalling employees' ability to external parties (Waldman, 1984). As a result, adverse selection occurs, leading to lower turnover rates for the company and a lower amount of employment offers for the firm's employees from external parties (Greenwald, 1979; Baker, Gibbs \& Holmstrom, 1994). Incentive provision on the other hand refers to rewarding employees for their past performance through higher pay and status within the company. An important concept in both functions of promotions is the perceived fairness of evaluation (Feather, 1999). Employees expect there to be a constant relationship between action (dimensions of evaluations that employees influence through their behaviour) and result (the promotion). However, if the relation between action and result changes depending on the type of promotion incentive as different ability measures are applied, and if employees do not have fully transparent insight into why this relation changes, it may be perceived as unfair. As a result, employees' performance would decrease due to frustration and lower motivation. The focus of this research is rather on the incentive provision role of promotions than the matching role, and this paper is consequently adding to the incentive contracting literature. However, it should be noted that depending on the incentive provided, the incentive provision role may not necessarily conflict with the matching role, as research has shown that the two promotion functions may also be complementary under certain settings (Grabner \& Moers, 2016).

Only a relatively limited amount of empirical research has been conducted in the area of promotion incentives and effort provision. Campbell (2008) empirically investigates a similar relationship as examined in this paper by analysing data from a U.S.-based fast-food retailer. In his study, Campbell (2008) aims to investigate the sensitivity of promotion decision to service quality provided. His findings imply that promotion opportunities generally lead to higher service quality performance. While Campbell (2008) estimates performance based on service quality provided, this paper uses a formula-based measure of sales performance regarding employees that are subject to a promotion incentive. Campbell (2008) measures service quality based on customer perceptions, meaning that the data for this measurement are not internally created by the firm. Thus, it is assumed in his study that this externally generated variable accurately reflects internal changes in effort provision. This paper challenges this assumption and views internal measures of sales performance as a more accurate proxy. Furthermore, the data used in this paper is collected from a firm in the Swiss retail banking industry as opposed to the U.S. fast food industry data used by Campbell (2008). As a result, additional industry-and country-specific differences may be identified.

In a recent study, Chan (2016) investigates in an experimental setting how the provision of relative performance indicators affects employee performance when promotion opportunities are provided. Chan (2016) assumes that a promotion is always associated with a change in tasks, meaning that the job after the promotion always requires higher abilities than the previous one in his experiment. In contrast, this paper differentiates between promotions to a similar task environment (Type $S$ ) and those to a different task environment (Type D), consistent with Grabner \& Moers (2013). Consequently, it differs from Chan's (2016) study to the extent that it represents an empirical field study rather than an experimental setting and does not make the mentioned assumption regarding the change in tasks but rather investigates how the impact of promotion opportunities may differ depending on the type of promotion incentive provided.

\footnotetext{
$22 \mid$\begin{tabular}{l|l} 
Marble \\
Research
\end{tabular} Papers
} 
There are a few other studies addressing different incentive effects of promotions, such as Medoff \& Abraham (1980) or Baker, Gibbs, \& Holmstrom (1994). However, these studies are rather descriptive and lack empirical evidence about the issue addressed by this research. Consequently, this paper aims to improve understanding of promotions' incentive function by providing such empirical evidence.

\section{Formulation of Hypotheses}

\subsection{Hypotheses}

\subsubsection{Type S Incentive Hypothesis}

As discussed in the literature review, only a limited amount of empirical research has been conducted to investigate the relationship between promotion incentives and effort provision. In the only study that could be identified testing a similar relationship as proposed in an empirical field study, Campbell (2008) finds that promotion opportunities generally lead to higher service quality performance. Consequently, the general expectation in this study is that promotion opportunities have a positive impact on effort provision. However, promotions may be further categorized based on the tasks performed after promotion as compared to tasks performed in the current job. If there is a major change in tasks performed, it is referred to as a Type $D$ (different) promotion; if there is only a minor change, it is referred to as a Type S (similar) promotion, consistent with Grabner \& Moers (2016). Grabner and Moers (2016) find that these different promotion types are related to different training programs that employees attend in the context of human capital acquisition. Furthermore, factors considered by management in promotion decisions may differ in Type D and Type S settings. Specifically, in Type S settings, management is likely to rely more on current job performance indicators than in Type $D$ settings where other measures of ability may have higher importance (Grabner \& Moers, 2013). The reason for the expectedly increased importance of the current job performance in Type $S$ settings is that the performance in the current job is likely to be highly correlated with the performance in the job after the promotion as the employee performs similar or even the same tasks afterwards. Thus, current job performance appears to be a suitable and relatively straight forward assessment of ability and perceived as fair by both employers and employees (Feather, 1999). Consequently, it is hypothesized that since managers are expected to consider an employee's current job performance when making promotion decisions in Type $S$ settings, the impact of promotion opportunities on effort provision is positive in Type S settings.

\section{H1: Type S Promotion Incentives have a positive impact on effort provision.}

\subsubsection{Type D Incentive Hypothesis}

In contrast, in Type D settings, employers are likely to consider a different set of ability indicators when evaluating the suitability of an employee for promotion. Since the tasks to be performed change after the promotion in the Type $D$ setting, current sales performance is expected to be a worse indicator of an employee's ability to perform well after the promotion than in Type $\mathrm{S}$ settings. After the promotion, the employee may be more preoccupied with for example administrational tasks rather than closing as many sales as possible, and the ability to perform these other tasks may be better evaluated with other indicators. In this context, Grabner \& Moers (2016) find that Type D promotions in particular incentivize 
employees to invest in human capital through training that is relevant to the next job. Furthermore, the perceived fairness of the promotion evaluation may also play an important role. Employees may expect that those colleagues with the best performance are the ones that deserve a promotion the most. This means that they expect there to be a consistent relation between action and result (Chan, 2016; Feather, 1999) and if this expectation is not met, it is perceived as being treated unfairly by the employer. Thus, if the relation between action and result changes depending on the different types of promotion incentives, and if employees do not have fully transparent insight into why this relation changes, it is perceived as unfair. In such situations in which employees are uncertain about how the employer evaluates them, it is likely that employees expect it to be fairer to promote those employees with a high current job performance. This is because their current job performance can be influenced by their actions, while other ability measures are harder or even impossible to control as an employee, especially if employees are not fully aware on which basis the ability measurements are made (Chan, 2016). Consequently, it is expected that a higher sales performance still has a positive impact when the employee is evaluated, as it is a way to distinguish oneself from other promotion candidates and may signal for example that the employee is a hard worker. However, as other indicators of ability are also likely to be considered by the employer, it is probable that the importance of sales performance is lower in Type D settings than in Type S settings.

\section{H2: Type D Promotion Incentives have a positive impact on effort provision.}

The proxy used to measure effort provision is Sales Performance, which is a formula-based measure comparing expected and actual sales performances. It is important to note that Sales Performance is measured before any promotion, i.e. during the time period in which the employee is subject to any promotion incentive. Thus, when the term Sales Performance is used in this paper, it refers to current sales performance given a Type S or Type D Incentive.

The following figure briefly depicts and summarizes the two main hypotheses of this paper. As explained above, both types of incentives are expected to have a positive relationship on effort provision. However, as indicated by the smaller plus-sign on the node of the Type D Incentive in the Figure, it is expected that the positive coefficient is smaller for the Type $D$ than for the Type $S$ Incentive.

Figure 1 - Hypotheses Model

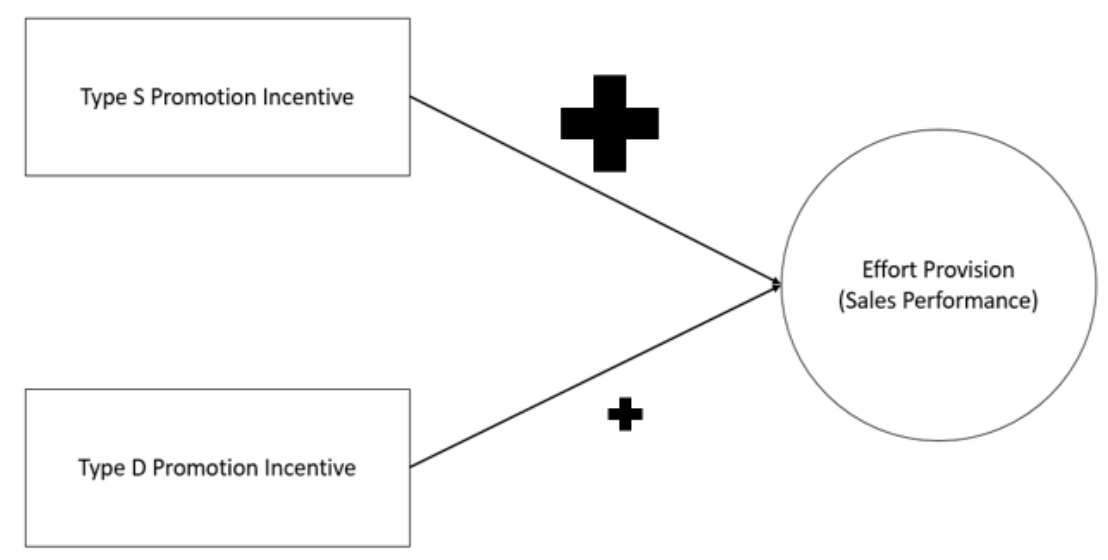

\footnotetext{
$24 \mid \begin{aligned} & \text { Marble } \\ & \begin{array}{l}\text { Research } \\ \text { Papers }\end{array}\end{aligned}$
} 


\subsection{Control Variables}

A variety of control variables is introduced in addition to the variables that are discussed in the previous section (Type S Incentive, Type D Incentive, and Sales Performance). The meaning of the control variables used and the reasoning for including them is discussed in this section.

The first control variable used is Gender, which is a dummy variable equal to 1 if the employee is male, and equal to 0 if the employee is female. This variable is included as male and female employees may act differently when provided with a promotion opportunity. However, there is no prediction in which direction this variable influences effort provision. Thus, there is no indication whether male employees may provide more effort, less effort or equal effort as compared to female employees when provided with a promotion incentive. The second control variable integrated in the model is JobTenure, which measures the time in years that an employee has remained in his or her current job. One may argue that as JobTenure increases, experience and ability of the employee increases, making him or her more suited for the promotion (Grabner and Moers, 2016; Gibbons and Waldman, 1999). However, it is also possible that employees with a high amount of JobTenure have accumulated a lot of time in their current job because they are not suited for promotion, thus being 'leftovers'. In terms of the Peter Principle (Chan, 2016; Fairburn \& Malcomson, 2001; Grabner \& Moers, 2013), these employees may already have been promoted to their level of incompetence. As shown by these different arguments, there is no directional prediction for this variable.

Another control variable implemented is called HierLevel, which is an employee's hierarchical level within the company; the lower this variable, the higher the employee's hierarchical level. Employees higher in the hierarchy may have a lower sales performance as they are likely to be more preoccupied with administrational or managerial tasks. However, it is possible that these employees higher in the hierarchy were promoted because of their superior sales performance, and they consequently may outperform lower hierarchical levels despite other tasks they are expected to perform. It is even possible that the expected sales performance is adjusted downwards if the employees who are higher in the hierarchy are also required to perform other additional tasks. Gibbons \& Murphy (1992) argue that promotion incentives may have a more significant impact on those employees lower in the hierarchy. They argue that the immediate increase in compensation as well as the eligibility for future promotions impact these employees more than those already higher in the hierarchy. As the incentive may be stronger for these employees, they may adjust their sales performance differently. Thus, the reasoning for including this variable is to control for hierarchical performance differences and no directional prediction is made as different arguments seem reasonable. Furthermore, the Size variable indicates the number of employees in the branch of the bank which the employee-year observation is referring to. It is possible that Size affects the relative likelihood to be promoted. For example, it is expected that there are more promotion incentives present in a larger branch. However, an employee in such a branch also needs to compete with a higher number of other employees for the promotion. Consequently, it is reasonable to expect that an employee adjusts his or her effort provision depending on the perceived likelihood to be promoted, which should depend on the total number of employees competing for the promotion, as well as the frequency in which the promotion incentive is provided. As the relationship between the number of employees competing for promotion and frequency of the promotion incentive is difficult to estimate without prior empirical analysis, no directional prediction is made. 
Moreover, the control variable AvrJobLength is integrated in the analysis. This variable represents the average amount of time that an employee has worked at a job at the bank. Thus, in contrast to JobTenure, the variable does not only include the current job, but also previous jobs of the employee at the bank. This implies that if the employee only had one job at the company, AvrJobLength is equal to JobTenure. Consistent with Grabner and Moers (2016), it is predicted that AvrJobLength is negatively correlated with Sales Performance, as employees with a low AvrJobLength are likely to be high performers. Furthermore, the control variable Full is a dummy variable that equals 1 if the employee is working full-time at the bank, and 0 otherwise. This variable is included as it is possible that a promotion affects full- and part-time employees differently. While the total amount of additional salary gained from a promotion should be higher for employees working full-time, the relative increase in compensation should be similar between a part- and fulltime working employee. Since employees may take both the total increase and the relative increase, or even only either of them, into account when adjusting his or her effort provision, no directional prediction is made.

Furthermore, the Switch variable is a dummy variable that equals 1 in the year in which an employee switches branches, and 0 otherwise. On one hand, after switching branches, an employee's sales performance may drop as he or she needs to adjust to the new working environment. On the other hand, the performance may also increase as the employee already is familiar with the company's policies and procedures and may be more motivated to make a good impression, especially if the employee initiated the switch him- or herself. Thus, no prediction is made regarding the sign of this variable. Finally, four dummy variables called Yr2005, Yr2006, Yr2007, and Yr2008 are introduced. As the panel data is measured in employee-year specific observations, these dummy variables indicate the year in which the performance is measured (Yr200X is equal to 1 in the year 200X in which the observation is made, with all other Yr dummy variables being equal to 0 ). These variables are introduced to account for year-specific effects. For example, economic changes may impact the ability to meet the sales target (external), or the bank may have changed its policy in establishing target performances (internal). As I do not have information about internal changes regarding policies, and there is a variety of external factors that may influence sales performance, no directional prediction is made for either of these four dummy variables.

\section{Methodology}

\subsection{Research Question}

The overall aim of this research paper is to enhance understanding of the implicit incentive effects of promotion opportunities on effort provision by providing relevant empirical evidence. This is an important relationship to analyse due to its possible effects on the principal-agent relationship. A credible promotion incentive may reduce the inherent conflict between these two parties as the agent is likely to provide additional effort when provided with such an incentive. Furthermore, as identified in the literature review, there are relatively few studies which empirically address this topic, making it a promising area to investigate. Consequently, the following research question will be addressed throughout this paper: How do implicit incentives provided through promotion opportunities affect effort provision?

\footnotetext{
$26 \mid$\begin{tabular}{l|l} 
Marble \\
Research
\end{tabular} Papers
} 


\subsection{Sample Selection}

This paper uses panel data collected from a Swiss retail bank. The dataset was provided by the Accounting and Information Management Department of Maastricht University. The data is addressing a time frame of six years (2004-2009) and shows information about a total of 5668 observations, each relating to a specific employee-year. Furthermore, the dataset provides a foundation to address the research question as it provides detailed information about employee movements between the different branches of the bank. While in some branches, an employee is provided with a promotion incentive, there are other branches in which such an incentive is absent. As a consequence, the assessment of the implicit promotion incentive is enabled through measurement of the employees' movements between branches. Due to scope limitations of this research project, no additional interviews or surveys with employees of the retail bank could be performed. Thus, no further qualitative information from employees and managers of the bank could be integrated to explain or further build on findings.

\section{Analysis}

Two-Step Generalized Method of Moments (IV GMM) tests are conducted to test the causal effect of promotion opportunities on effort provision; the test is run once for the Type S Incentive and once for the Type D Incentive. The IV GMM is particularly suited for analysis as microeconomic panel data is used. With such data, there is the possibility of endogeneity issues, i.e. correlations between explanatory variables and the error term which the IV GMM test addresses.

\subsection{Type S Incentive Analysis}

In the first step of the IV GMM analysis, the following regression is conducted for the Type S Incentive:

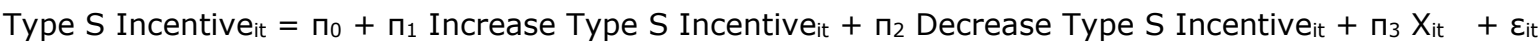

The dependent variable Type S Incentive $e_{i t}$ is a dummy variable equalling 1 when the incentive is present and 0 when it is absent. The measurement of increases and decreases in Type $S$ Incentives is enabled by data on employees' switches between the branches of the bank. An employee may switch from a branch with an incentive to a branch without an incentive (incentive to no incentive), from a branch without an incentive to a branch with an incentive (no incentive to incentive), from a branch with an incentive to a branch where the incentive is present as well (no change incentive), and finally form a branch without an incentive to a branch where the incentive is also absent (no change no incentive). The first-stage regression of the IV GMM only includes the no incentive to incentive (called Increase Type S Incentive) and incentive to no incentive (called Decrease Type S Incentive) cases. Both no change incentive and no change no incentive variables are not included in the model as the aim of this first stage regression is to identify how changes in the instruments affect the Type $S$ Incentive. The variable Increase Type $S$ Incentive $e_{i t}$ is a dummy variable which equals 1 when there is an increase in the Type S Promotion Incentive, and 0 otherwise. Similarly, the variable Decrease Type S Incentive it is equal to 1 when there is a decrease in the Type S Promotion Incentive, and 0 otherwise. Finally, $\mathrm{X}_{\text {it }}$ is a vector consisting of the control variables 
discussed in the previous section (Gender, JobTenure, HierLevel, Size, AvrJobLength, Full, Switch, Yr2005, Yr2006, Yr2007, and Yr2008). The second-stage regression for the Type S Incentive is defined as follows:

Sales Performance $i t=\beta_{0}+\beta_{1}$ Type S Incentive $e_{i t}+\beta_{2} X_{i t}$

The variable Sales Performance ${ }_{i t}$ is a formula-based measure comparing expected and actual sales performances; the other variables in the second-stage regression are already explained above. In order to draw conclusions from these analyses, the data must be both relevant and valid. The Type S GMM IV model has an F-Statistic of 19.14 (significant at $1 \%$ ), and an Uncentered $\mathrm{R}^{2}$ of $8.22 \%$ (see Table 2). A total of 1847 observations were included in the analysis. Furthermore, the Kleibergen-Paap F-statistic (equal to 17.63 ) rejects the null hypothesis of weak instruments at $1 \%$. Consequently, the instruments used in the Type $\mathrm{S}$ model are relevant. In order to test exogeneity (validity), the Hansen-J Statistic is applied. For the Type S model, this statistic is equal to $2.427(\mathrm{p}=11.92 \%)$ and cannot be rejected at the $10 \%$ level. As the null hypothesis of the Hansen-J test is that there is no correlation between explanatory variables and the error term, not rejecting this hypothesis means that the variables used are exogeneous (valid). Thus, reliable conclusions can be drawn from the Type $S$ analysis as the instruments are both relevant and valid. The output of the two-step GMM IV for the Type $S$ analysis is shown in Table 1 and will be addressed in the Discussion section.

\subsection{Type D Incentive Analysis}

Similar to the Type S Incentive, the first-stage regression for the Type D Incentive is defined as follows:

Type D Incentive $_{i t}=\Pi_{0}+\Pi_{1}$ Increase Type D Incentive $_{i t}+\Pi_{2}$ Decrease Type D Incentive $_{i t}+\Pi_{3} X_{i t}+\varepsilon_{i t}$

The variables are consistent with the descriptions regarding the first-stage IV GMM regression for the Type $S$ Incentive; only the type of the incentive changed from Type $S$ to Type $D$ as compared to the previous section: Type $D$ Incentive it is a dummy variable equal to 1 when the Type $D$ Incentive is present, Increase Type $D$ Incentive is equal to 1 when there is an increase in the Type D Incentive, and Decrease Type D Incentive is equal to 1 when there is a decrease in the Type $D$ Incentive. $X_{i t}$ is a vector consisting of the same control variables that were mentioned in the first-stage regression of the Type $S$ Incentive. The second-stage regression for the Type $D$ Incentive is defined as:

Sales Performance $i t=\beta_{0}+\beta_{1}$ Type D Incentive $i t+\beta_{2} X_{i t}$

The Type D GMM IV model has an F-Statistic of 33.56 (significant at 1\%) and an Uncentered $\mathrm{R}^{2}$ of $8.97 \%$ (see Table 4). A total of 2858 observations were included in the analysis. In addition, the Kleibergen-Paap F-statistic (equal to 25.86 ) rejects the null hypothesis of weak instruments at $1 \%$. The Hansen-J Statistic is equal to $1.472(p=22.5 \%)$, thus the null hypothesis of valid instruments is not rejected. Consequently, reliable conclusions can also be drawn from the Type $D$ analysis as the instruments are both relevant and valid. The output of the two-step GMM IV analysis for the Type D analysis is shown in Table 3 and will be discussed in the next section. 
Table 1 - Two-step GMM, Type S Promotion Incentive

\begin{tabular}{|l|l|}
\hline Variables & Sales Performance \\
\hline Type S Inventive & $24.229 * * *$ \\
& {$[2.710]$} \\
\hline Gender & 3.119 \\
& {$[0.870]$} \\
\hline Job Tenure & -0.342 \\
& {$[-0.450]$} \\
\hline HierLevel & 1.122 \\
\hline Size & {$[0.330]$} \\
\hline & -0.066 \\
\hline AvrJobLength & {$[-0.240]$} \\
\hline Full & -0.316 \\
& {$[-0.590]$} \\
\hline Switch & 0.896 \\
& {$[0.180]$} \\
\hline Yr2005 & -2.636 \\
& {$[-0.460]$} \\
\hline Yr2006 & $25.534 * * *$ \\
& {$[7.380]$} \\
\hline Yr2007 & $38.587 * * *$ \\
& {$[8.960]$} \\
\hline Yr2008 & $31.408 * * *$ \\
& {$[7.150]$} \\
\hline Constant & 1.621 \\
& {$[0.430]$} \\
\hline & -48.949 \\
& {$[-0.86]$} \\
\hline
\end{tabular}

1) The sample size relates to employee-years and covers the time period 2004-2009. The instruments used in the first step of the IV GMM are "Increase Type S Incentive" and "Decrease Type S Incentive". Zstatistics based on robust standard errors are shown in [brackets] and are adjusted for clustering within groups.

$2) *, * *, * * *$ is significant at 10 percent, 5 percent, and 1 percent, respectively (two-tailed).

Table 2 - Additional Statistical Information about Type S Incentive IV GMM

\begin{tabular}{|l|l|}
\hline Statistical Information & Value \\
\hline Observations & 1847 \\
\hline Uncentered $\mathrm{R}^{2}$ & $8.22 \%$ \\
\hline $\mathrm{F}(12,54)$ & 19.13 \\
\hline $\mathrm{P}>\mathrm{F}$ & 0.0000 \\
\hline Kleibergen-Paap rk LM & 17.63 \\
\hline Chi-Square (2) P-Value & 0.0001 \\
\hline Hansen J & 2.427 \\
\hline Chi-Square (1) P-Value & 0.1192 \\
\hline
\end{tabular}


Table 3 - Two-step GMM, Type D Promotion Incentive

\begin{tabular}{|l|l|}
\hline Variables & Sales Performance \\
\hline Type D Inventive & 0.086 \\
\hline Gender & {$[0.01]$} \\
\hline Job Tenure & 2.145 \\
& {$[0.80]$} \\
\hline HierLevel & 0.122 \\
& {$[0.35]$} \\
\hline Size & -2.446 \\
& {$[-1.21]$} \\
\hline AvrJobLength & 0.049 \\
\hline & {$[0.229]$} \\
\hline Full & $-0.344 *$ \\
& {$[-2.07]$} \\
\hline Switch & -3.656 \\
& {$[-1.34]$} \\
\hline Yr2005 & $-7.423^{* *}$ \\
& {$[-1.98]$} \\
\hline Yr2006 & $26.257 * * *$ \\
& {$[15.44]$} \\
\hline Yr2007 & $22.852^{* * *}$ \\
& {$[9.79]$} \\
\hline Yr2008 & -0.455 \\
& {$[-0.20]$} \\
\hline Constant & -0.017 \\
& 31.791 \\
\hline & 31.791 \\
& {$[0.93]$} \\
\hline
\end{tabular}

1) The sample size relates to employee-years and covers the time period 2004-2009. The instruments used in the first step of the IV GMM are "Increase Type D Incentive" and "Decrease Type D Incentive". Zstatistics based on robust standard errors are shown in [brackets] and are adjusted for clustering within groups.

$2) *, * *, * * *$ is significant at 10 percent, 5 percent, and 1 percent, respectively (two-tailed).

Table 4 - Additional Statistical Information about Type D Incentive IV GMM

\begin{tabular}{|l|l|}
\hline Statistical Information & Value \\
\hline Observations & 2858 \\
\hline Uncentered $\mathrm{R}^{2}$ & $8.97 \%$ \\
\hline $\mathrm{F}(12,54)$ & 33.56 \\
\hline $\mathrm{P}>\mathrm{F}$ & 0.0000 \\
\hline Kleibergen-Paap rk LM & 25.86 \\
\hline Chi-Square (2) P-Value & 0.0000 \\
\hline Hansen J & 1.472 \\
\hline Chi-Square (1) P-Value & 0.2250 \\
\hline
\end{tabular}

\footnotetext{
30 Research 


\section{Discussion}

In this section, the output of the Type $S$ and Type $D$ analyses will be interpreted. As shown in the Analysis section, the output is both relevant and reliable for the Type $S$ as well as the Type $D$ analysis. The Type $S$ Incentive analysis will be discussed first (see Table 1), while the Type D Incentive output will be addressed afterwards (see Table 3).

Regarding the Type S Incentive analysis, the output indicates that four of the variables included in the model have a significant impact on Sales Performance. Most importantly, the Type S Incentive has a positive effect on Sales Performance and is significant at the $1 \%$ level, i.e. the findings are as expected for the Type S Incentive. The analysis fails to reject Hypothesis 1: Type S Promotion Incentives have a positive impact on effort provision. The other significant variables are Yr2005, Yr2006, and Yr2007 which all have a positive impact on Sales Performance and are significant at the $1 \%$ level. However, there could be a variety of reasons why these year specific variables affect Sales Performance; both internal and external factors have to be considered. For example, the financial crisis of banking industry may have caused the actual sales performance in 2008 to drop as compared to previous years. As it would then be lower than the expected sales performance that was established previously, the Sales Performance variable would be relatively lower in that year as compared to previous years which had a high sales performance due to a well performing economy. Alternatively, there may have been a change in how sales targets are established over the years. Most likely, the year specific dummy variables reflect a combination of both internal and external factors. In order to further understand the significance and potential causes of these year-specific effects, interviews with the bank's personnel would need to be conducted.

Regarding the Type D Incentive, there are also four variables that have a significant impact on Sales Performance according to the IV GMM analysis. However, the main variable of interest as identified in the second hypothesis, namely the Type D Incentive, is insignificant. Consequently, Hypothesis 2 is rejected: Type D Promotion Incentives do not have a positive impact on effort provision. It is likely that employees rather signal their suitability for promotion through channels other than their performance in their current job. For example, Grabner \& Moers (2016) find that Type D promotions in particular incentivize employees to invest in human capital through training that is relevant to the next job. However, as such training represents a time investment, the employee may be trading off time he or she would have spent on relevant sales performance activities instead and as a result, sales performance drops. Accordingly, there seem to be evaluation criteria that are more important in Type D settings which employees shift their attention towards, and thus it appears likely that employees are also aware of these criteria. This does not necessarily imply that an employee would not be able to communicate suitability regarding some aspects that are also desirable after the promotion (such as being a hard-working employee) through sales performances at all. Instead, there seem to be other channels which are preferred when communicating suitability. There are likely to be other channels next to investment in training relevant to the next job that Grabner and Moers (2016) identify. For example, taking on additional responsibilities or increasing the amount of overtime hours provided may be incentivized by the Type D Incentive.

According to the Type D Incentive IV GMM analysis, there are four variables that have a significant impact on Sales Performance: AvrJobLength, Switch, Yr2005, and Yr2006. AvrJobLength has a negative effect on Sales Performance and is significant at the $5 \%$ level. This is in line with the prediction made in section 4.2. Employees that have a low average job length at the bank are likely to be high performers with high potential who quickly climb up in firm's hierarchy. In contrast, employees with high AvrJobLength may be

The Implicit Incentive Effects of Promotion Opportunities on Effort Provision 
'leftovers' which may have already been promoted to their level of incompetence in terms of the Peter Principle (Chan, 2016; Fairburn \& Malcomson, 2001; Grabner \& Moers, 2013). Furthermore, the Switch variable has a negative impact on Sales Performance, and is significant at the $5 \%$ level. This may indicate that employees have a lower sales performance due to the need to get adjusted to the environment at the new branch in the year of the switch. Alternatively, in cases of forced relocations of employees, performance may drop due to lower morale. Finally, Yr2005 and Yr2006 have a positive impact on Sales Performance that is significant at the $1 \%$ level. Interestingly, the Yr2007 variable that was significant and had a strong positive effect on Sales Performance in the Type $\mathrm{S}$ analysis, is slightly negative and insignificant in the Type $D$ analysis. Thus, the impact of year-specific events also seems to differ depending on which type of promotion incentive is included in the model. As already argued in the discussion of the Type S Incentive analysis, there may be a variety of reasons for the significance of these year specific control variables which may be possible to further narrow down by inquiry of the bank's personnel.

\section{Implications and Limitations}

\subsection{Implications}

This paper adds to the understanding of the implicit incentive effects of promotions and is rooted in the incentive contracting literature. Generally, when analysing the incentive functions of promotions, it appears to be important to make a distinction between different types of promotion opportunity provided. This paper differentiates between promotion opportunities to jobs where similar tasks as in the current job are performed in the job after the promotion (Type S) and promotion opportunities to jobs where different tasks are performed in the job after the promotion (Type D). Similar to Grabner and Moers (2016), findings differ depending on these subcategories of promotion incentives. Therefore, by providing empirical evidence, this paper partly confirms established frameworks regarding the effects of promotion incentives while directing attention to the different categories of incentives that were initially identified by Grabner and Moers (2016). However, the findings are not only value adding for the incentive contracting literature, but may also be of relevance for practitioners. In fact, companies may have realized that they do not achieve an expected level of increase in sales performance by simply providing employees with the opportunity to get promoted. This paper's findings highlight that firms should consider that there are differences regarding the effect of provided promotion opportunities depending on the characteristics of the opportunity, as suggested by the results that were identified in the analysis between Type D and Type $S$ Promotion Incentives.

While Type S Promotion Incentives appear to increase the sales performance of employees, the insignificant relation between Sales Performance and the Type D Promotion Incentive does not necessarily imply that employees provided with this incentive do not change their behavior at all. Rather, an employee may provide higher effort in areas other than sales performance, such as investing in his or her human capital through training (Grabner and Moers, 2016). Consequently, promotion incentives may affect various dimensions through which an employee wants to communicate his or her suitability for the promotion. The weighting which an employee puts on each dimension appears to depend on the promotion incentive provided. Referring to the issue of interest alignment between principal and agent that was briefly discussed in the introduction, the increased understanding about the relation between promotion incentives and effort provision may help to achieve improved interest alignment. For example, despite

\footnotetext{
32 Research Papers
} 
findings such as Campbell's (2008) that promotion incentives have a positive impact on effort provision, it is possible that firms may have wondered why sales performance was not increasing by the predicted amount when providing employees with this kind of incentive. This paper offers a possible explanation, i.e. that not all kinds of promotion incentives provided are equal. Consequently, a better understanding about this incentive may increase the likelihood of firms considering it when developing compensation contracts (Gibbs, 1995).

\subsection{Limitations}

Nevertheless, there are a variety of factors that need to be considered regarding this paper's findings. First of all, there may be even further distinctions that can be made regarding the categories of promotion incentives. As such, there may be an issue that is similar to the argument that was made when comparing Campbell's (2008) findings with this paper's findings. For example, while Type S Promotion Incentives generally appear to have a positive impact on sales performance, a further distinction in future research may reveal that some Type $S$ Incentives have an especially large positive impact while other Type $S$ Incentives do in fact not have any significant impact. Furthermore, as apparent from the interpretations of the year effects in both analyses, this paper is subject to some inherent scope limitations. As a consequence of these scope limitations, no interviews with the bank's personnel could be conducted, which may have provided useful qualitative information. Such additional information may have been helpful in interpreting some findings of the analysis. In addition, using sales performance in order to measure effort provision may be a somewhat simplified approach. There may be a variety of ways in which an employee provides effort besides sales performance. While it is argued in this paper that based on the available data about the bank in Switzerland., sales performance represents the single variable that is most highly related to effort provision, it seems reasonable to expect that effort provision represents a multidimensional variable itself. As Campbell (2008) argues, "promotion decisions tend to share similar features to subjective performance evaluation, including a reliance on a combination of observable measures of performance, subjective evaluations of employees by superiors, and the subjective weighting of the importance of various observable performance measures". As the criteria employees are evaluated upon go beyond observable performance measures, it seems likely that employees provide effort not only through sales performance, but also through other channels with the aim to attain a favorable evaluation. For example, employees may take on additional responsibilities within the firm or invest in their education and training. Consequently, modelling effort provision as a multidimensional variable may improve the accuracy of this paper's model. Nevertheless, sales performance as used in the paper is viewed as a more accurate proxy for actual effort provision than proxies used in prior research identified in the literature review (see Campbell, 2008; Chan, 2016). Also, it is important to keep in mind that a multidimensional dependent variable would introduce an increased amount of complexity in this paper's model, which in turn would make interpretation of results more difficult.

\section{Conclusion}

The overall aim of this paper was to enhance understanding of implicit promotion incentives by empirically analysing the relationship between these incentives and effort provision. Consequently, this paper 
differentiated between promotions to jobs in which similar tasks as in the current job are performed (Type S) and promotions to jobs in which different tasks as in the current job are performed (Type D). Sales Performance, which is a formula-based variable comparing expected and actual sales performance, was used as a proxy for effort provision and measured in the time frame in which an employee is subject to the promotion incentive. The sample used in this research contained 5668 employee-year observations at a retail bank in Switzerland. The results indicate that Type S Promotion Incentives have a significantly positive impact on effort provision, while Type D Promotion Incentives do not have a significant impact on effort provision. Thus, it appears to be important to make this distinction between the Type S and Type D settings of promotion incentives. While Type $D$ promotions do not have a significant impact on Sales Performance, they may have a significant impact on other ways in which employees may adjust their behavior, such as undertaking an increased amount of training relevant to the job after the promotion (Grabner and Moers, 2016). In addition, although Type S promotions do have a significantly positive impact on Sales Performance, the incentives provided through these types of promotions may also affect other behavior within a company. Thus, as it seems plausible that Type D Promotion Incentives influence behavior in areas other than sales performance, it is likely that Type S Promotion Incentives also have an impact on other dimensions. Generally, this paper's discussion suggests that in Type S settings, measures of current performance are an important indicator that is used to compare the ability of employees for the next job, while in Type $D$ settings other ability indicators are more important. Also, while promotions are already widely used throughout companies, this paper's findings may enable more effective use of the incentives provided through these promotions, and thus improve interest alignment. Future research may further address the issue of promotion incentives and analyse the impact of these incentives on for example vacation days taken or overtime hours, or even how qualitative evaluations of the employee's performance are affected by these incentives. While it appears important to make a distinction between Type S and Type D Incentives, future research may identify dimensions on which to even further disaggregate the model of promotion incentives. As with the distinction made in this paper, such further disaggregation of the promotion incentive model may reveal for example that in fact only certain types of Type S Incentives affect effort provision and is thus a possibility that should be considered by future research.

\section{References}

Azariadis, C. (1975). Implicit Contracts and Underemployment Equilibria. Journal of Political Economy, LXXXIII (6), 1183-1202.

Baker, G., Gibbs, M., \& Holmstrom, B. (1994). The Internal Economics of the Firm: Evidence from Personnel Data. The Quarterly Journal of Economics, 109(4), 881-919.

Baker, G., Jensen, M., \& Murphy, K. (1988). Compensation and Incentives: Practice vs. Theory. The Journal of Finance, 43(3), 593-616.

Campbell, D. (2008). Nonfinancial Performance Measures and Promotion-Based Incentives. Journal of Accounting Research, 46: 297-332.

Chan, E. (2016). Promotion, Relative Performance Information, and the Peter Principle. AAA 2016 Management Accounting Section (MAS) Meeting Paper, 1-53.

\footnotetext{
34 Research Papers
} 
Cichello, M., Fee, C., Hadlock, C., \& Sonti, R. (2009). Promotions, Turnover, and Performance Evaluation: Evidence from the Careers of Division Managers. Accounting Review, 84(4), 11191143.

Coff, R. (1997). Human Assets and Management Dilemmas: Coping with Hazards on the Road to Resource-Based Theory. The Academy of Management Review, 22(2), 374- 402.

Ederhof, M. (2011). Incentive Compensation and Promotion-Based Incentives of Mid-Level Managers: Evidence from a Multinational Corporation. Accounting Review, 86(1), 131-153.

Fairburn, J. A., \& Malcomson, J. M. (2001). Performance, Promotion, and the Peter Principle. Review of Economic Studies, 68, 45-66.

Feather, N. T. (1999). Judgments of deservingness: Studies in the psychology of justice and achievement. Personality and Social Psychology Review 3, 86-107.

Fried, J., \& Howitt, P. (1980). Credit Rationing and Implicit Contract Theory. Journal of Money, Credit and Banking, 12(3), 471-487.

Garnefeld, I., Iseke, A., \& Krebs, A. (2012). Explicit Incentives in Online Communities: Boon or Bane?. International Journal Of Electronic Commerce, 17(1), 11-38.

Gibbons, R. (1998). Incentives in Organizations. Journal Of Economic Perspectives, 12(4), 115-132.

Gibbons, R. \& Waldman, M. (1999). A theory of wage and promotion dynamics inside firms. The Quarterly Journal of Economics, 114, 1321-1358.

Gibbs, M. (1996). Promotions and Incentives. Working paper, University of Chicago, 1-28.

Gibbs, M. (2008). Discussion of Nonfinancial Performance Measures and Promotion-Based Incentives. Journal of Accounting Research, 46: 333-340.

Grabner, I. \& Moers, F. (2013). Managers' Choices of Performance Measures in Promotion Decisions: An Analysis of Alternative Job Assignments. Journal of Accounting Research, 51: 1187-1220.

Grabner, I., \& Moers, F. (2016). Implicit Incentives for Human Capital Acquisition. Working Paper. Maastricht University.

Greenwald, B. (1986). Adverse Selection in the Labour Market. The Review of Economic Studies, 53(3), 325-347.

Heath, J. (2009). The Uses and Abuses of Agency Theory. Business Ethics Quarterly, 19(4), 497-528.

Medoff, J. \& Abraham, K. (1980). Experience, Performance, and Earnings. The Quarterly Journal of Economics, Vol. XCV (4), 703-736.

Prendergast, C. (1999). The Provision of Incentives within Firms. Journal of Economic Literature, 31, 7-63.

Waldman, M. (1984). Job Assignments, Signaling, and Efficiency. Rand Journal of Economics, XV, 25567. 